\title{
Unmanned aerial vehicles mitigate human-elephant conflict on the borders of Tanzanian Parks: a case study
}

\author{
Nathan Hahn, Angela Mrakatobe, Jonathan Konuche, Nadia de Souza \\ Julius Keyyu, Marc Goss, Alex Chang'a, Suzanne Palminteri \\ ERIC Dinerstein and David Olson
}

\begin{abstract}
Protected areas across the range of the African savannah elephant Loxodonta africana are increasingly being surrounded and isolated by agriculture and human settlements. Conflicts between people and crop-raiding elephants regularly lead to direct reprisals and diminish community support for conservation. We report on field trials in northern Tanzania that employed a new, humane way for wildlife managers to move elephants away from conflict zones, from distances of $>100 \mathrm{~m}$, thereby enhancing the safety of wildlife managers, farmers and elephants. We deployed 10 unmanned aerial vehicles (drones) piloted by five trained teams of wildlife managers in the Tarangire-Manyara and Serengeti ecosystems. Game Scouts deployed the drones opportunistically during crop-raiding events at the peak of the maize ripening period in 2015 and 2016. In 100\% of trials $(\mathrm{n}=51)$ elephants responded to the presence of a drone by departing rapidly from crop fields $(\mathrm{n}=38)$ and settlements $(n=13)$. The cost of five teams responsible for $617 \mathrm{~km}^{2}$ in Tarangire-Manyara was estimated to be USD 15,520 for 1 year, and all drones remained operational for the duration of the study. The initial success of this tool warrants further testing of the utility of small unmanned aerial vehicles as part of the toolbox for wildlife managers and communities dealing with high levels of conflict with wildlife.
\end{abstract}

Keywords Drones, elephants, human-elephant conflict, Tanzania, UAVs, unmanned aerial vehicles

\footnotetext{
Crop raiding is one of the most common and costly $\checkmark$ forms of conflict between people and elephants Loxodonta africana in Africa (Sitati et al., 2003; Parker et al., 2007), provoking both retaliatory killing of elephants, and animosity towards elephants and other wildlife among

Nathan Hahn (Corresponding author), Jonathan Konuche, Nadia de Souza, Alex Chang'a, Suzanne Palminteri, Eric Dinerstein and David Olson Biodiversity \& Wildlife Solutions, RESOLVE, 1255 23rd St. NW, Washington, DC, 20037, USA. E-mail nhahn@resolv.org

Angela Mwakatobe and Julius Keyyu Tanzania Wildlife Research Institute, Arusha, Tanzania

Marc Goss Mara Elephant Project, Indianapolis, USA

Received 25 May 2016. Revision requested 28 June 2016.

Accepted 3 August 2016. First published online 9 November 2016.
}

local communities (Sitati et al., 2003; Parker \& Osborn, 2006; Parker et al., 2007). Finding effective, low-cost methods to reduce crop raiding by elephants has become a priority for wildlife managers over the last 2 decades (Hoare, 1995, 2012, 2015; Barnes, 1999; Naughton et al., 1999). Farmers employ a range of measures to reduce crop raiding, including fire, drums, electric fences, early warning systems, and Capsicum (chilli) and beehive fencing (Osborn, 2002; Sitati et al., 2005; Parker \& Osborn, 2006; Kioko et al., 2008; Karidozo \& Osborn, 2015). Some crop protection measures are prohibitively expensive and farmers must rely on more traditional deterrents, such as fire and noisemakers (Graham \& Ochieng, 2008). Traditional techniques often require close proximity to elephants, increasing the chance of injury or death to people and elephants because frightened elephants can be aggressive. Actively defending crops also disrupts daily routines and school schedules, as farmers and their children must remain vigilant throughout the night during the harvest season.

In 2014 we observed elephants reacting swiftly and dramatically to small unmanned aerial vehicles (also known as drones) being used for aerial photography. The drones had blinking red and green lights and emitted a loud whirring noise. These observations prompted us to test the efficacy of drones operated by trained wildlife managers to move elephants out of conflict zones.

To test the use of drones as a human-elephant conflict mitigation tool the Tanzanian Wildlife Division identified two localities in northern Tanzania that experience high levels of human-elephant conflict and have dedicated teams to deal with it: the $617 \mathrm{~km}^{2}$ Burunge Wildlife Management Area on the north-west border of Tarangire National Park, and the $1,022 \mathrm{~km}^{2}$ Ikongoro-Grumeti Game Reserve on the western boundary of Serengeti National Park. Peak crop-raiding activity coincides with the ripening of maize Zea mays, the area's main crop, during May-August (Mwalyosi, 1981; Pittiglio et al., 2014).

At both sites Village Game Scouts patrol farmlands and respond to reports of crop raiding, supported by the Wildlife Division and District Game Offices. Before the trials were carried out Game Scouts conducted nightly patrols and employed a range of tactics to prevent human-elephant conflict, including illumination, blowing air horns, 
throwing chilli-laced firecrackers, shooting fireworks and firing rifles. These tactics are commonly used in close proximity to elephants but give little control over the direction a herd will move in response. Approaching scared or angry elephants exposes Game Scouts to grave danger.

The trials were conducted in Burunge Wildlife Management Area during February-March and MayAugust (the peak maize crop-raiding season) 2015 and in Ikongoro-Grumeti Game Reserve during the crop ripening period of March-April 2016. Four drone models were tested: Phantom 1, Phantom FC4O, Phantom 2 Vision, and Phantom 2 Vision+ (DJI, Shenzhen, China). All models produce similar whirring sounds and have identical red and green blinking lights. We conducted three 4-day workshops over 1 year to train Game Scouts in the necessary tactics and best practices for herding elephants effectively, safely and humanely from a distance, as well as how to maintain and repair the unmanned aerial vehicles (RESOLVE et al., 2016). The workshops trained 8-27 participants, among whom skilled pilots were identified to operate the vehicles thereafter. We maintained a 3:1 ratio of participants to trainers for every workshop, and wildlife managers trained in the initial workshops acted as trainers on subsequent training courses, and as technical resource specialists during the trial period for the use of drones by human-elephant conflict response teams.

In both study areas, rangers locate elephants through existing informal reporting networks through which communities report conflict incidences to wildlife managers. Prior to the deployment of the drones, District Game Officers attended community meetings and made local farmers aware of the new tactics being introduced for human-elephant conflict mitigation. Once elephants were located, teams of rangers deployed the drones from an open-bed field vehicle to herd the elephants back into wildlands, from a safe distance $(>100 \mathrm{~m})$. Thermal cameras were prohibitively expensive, and therefore pilots flew by line of sight and used a 2,200 lumen FATMAX flashlight (Stanley Black \& Decker, New Britain, USA) to spotlight elephants during night flights, following departing elephants in vehicles. During day trials the teams used live video from a camera on the drone, streamed to a tablet, to assist in herding elephants.

Teams collected response data using a standardized scoring system adapted from Langbauer et al. (1991), Poole (1999), O'Connell-Rodwell et al. (2006) and Soltis et al. (2014). Trials were conducted opportunistically during regular Game Scout human-elephant conflict patrols. In each trial Game Scouts scored elephant responses as one of four distinct behaviours: (1) no response; (2) vigilance response; (3) flight response; or (4) aggressive response. The dominant behaviour displayed over 6o-second intervals was noted for the first 10 minutes of the flight, with minute zero defined as the time the drone was launched. We excluded trials where elephants began to flee before the drone was launched. We verified the incident data through debriefing sessions with the pilots at the end of each testing period.

We evaluated 51 trials of drones intercepting elephants in or near crops $(\mathrm{n}=38)$ or in or near community settlements $(n=13)$. Mean herd size was $14 \pm$ SE 1.3 elephants. Crops included a combination of maize, peas and beans. Forty-six trials were conducted at night (18.00-06.00) and five during the day (06.00-18.00). In all 51 trials, elephants began to show flight response behaviour within 1 minute of drone launch (normally within the first 30 seconds) for all elephant group types ( 38 family herds, 12 bull herds, one individual). As the drone approached, herds would group together quickly and flee rapidly as the drone came within c. $50 \mathrm{~m}$ of the closest individual.

Game Scouts were able to control the movement of the elephants through herding tactics, positioning the drone on either flank of the herd. The mean flight time was $18 \pm$ SE 1.5 minutes, and in 23 trials (45\%) Game Scouts were required to change the drone's battery during the mission. In all trials the elephants' flight behaviour was sustained as they were herded by the drone, until they were moved to what was deemed to be a safe distance from the crop or settlement area, typically $>_{1} \mathrm{~km}$. Elephants did not return to the fields later in the day or evening, according to reports from pilots and farmers. According to anecdotal evidence from farmers, and debriefs with Game Scouts, farmers were pleased with the new conflict-mitigation tool and the swift removal of elephants from their fields. The Game Scouts did not need to use any other deterrent methods during the months the drones were tested.

Four pilots flew the vehicles in 10 separate zones within the Burunge Wildlife Management Area, and three pilots flew in five zones within Ikongoro-Grumeti Game Reserve, with no apparent differences in elephant response between sites. The elephants in Burunge consistently reacted strongly to the drones over two seasons, which suggests that habituation did not occur over the study period. The number of family groups encountered raiding crops was higher than that of bull groups and lone bulls. This may be attributable, in part, to the difficulty of locating lone bulls in farming areas, compared to a large family herd. Furthermore, bulls may depart more rapidly on hearing Game Scout vehicles.

At the time of testing, one drone kit cost USD 955. Including maintenance, it cost c. USD 15,520 to equip two teams and operate the drones during the first year in Burunge Wildlife Management Area (Table 1). These teams patrol and respond to human-elephant conflict incidents throughout the entire Wildlife Management Area. The teams also support community-based methods, such as chilli fences (sisal fences soaked in engine oil with chilli powder) and chilli briquettes (burned chilli-laced elephant dung), which are low-cost and seasonal deterrents that 
TABLE 1 Costs associated with establishing and maintaining unmanned aerial vehicle deployment teams and Game Scout training programmes in the Burunge Wildlife Management Area in Tanzania, based on 2014-2015 trials. Direct training costs do not include salaries. The unmanned aerial vehicle kit costs are calculated based on the need for three vehicles (two active and one reserve) to support the two human-elephant conflict response teams in the Burunge Wildlife Management Area in 2015. Recurring costs are based on 1 year of operation and reflect the actual rate of maintenance over the course of 16 months of operation in Burunge (November 2014-February 2016). Several unmanned aerial vehicle models were used; the cost assessment is based on the cost of the base model, the Phantom 2 with no camera, in 2016.

\begin{tabular}{lrr}
\hline Item & \multicolumn{1}{c}{$\begin{array}{l}\text { Unit cost } \\
(\text { USD })\end{array}$} & \multicolumn{1}{c}{$\begin{array}{l}\text { Annual cost } \\
(\text { USD })\end{array}$} \\
\hline Unmanned aerial vehicle kits & $500(\times 3)$ & 1,500 \\
$\quad$ Phantom 2 & $150(\times 3)$ & 450 \\
$\quad$ Backpack carrying case & $90(\times 6)$ & 540 \\
$\quad$ Extra batteries (2 per vehicle) & $10(\times 15)$ & 150 \\
$\quad$ Extra prop pairs & $25(\times 3)$ & 75 \\
Power inverter & $50(\times 3)$ & 150 \\
Walther searchlight & 825 & 2,865 \\
Subtotal kits & 6,500 & 6,500 \\
Direct workshop costs & 700 & 1,400 \\
Direct recurring training costs & $10(\times 6)$ & \\
Annual recurring costs & $90(\times 4)$ & 60 \\
$\quad$ Propellers & $100(\times 3)$ & 360 \\
Batteries & & 720 \\
Peripherals & & 15,520 \\
Subtotal annual recurring costs & & \\
Total &
\end{tabular}

offer complementary, community-based solutions that can be applied across human-elephant conflict landscapes (Karidozo \& Osborn, 2015; Chang'a et al., 2016).

The consistent success of drones as a mitigation tool during three crop seasons and among different elephant populations, the rapid adoption of this mitigation tool by Game Scouts, and favourable reactions from local farmers suggest that drones have the potential to be an effective, long-term and cost-effective tool for human-elephant conflict mitigation. Their success during all of the night trials $(n=43)$ is particularly encouraging, as the dusk-to-dawn period is a notoriously challenging time to move elephants. Unmanned aerial vehicles are also easy to bring in and out of operation as crops ripen, and can be shifted rapidly to areas of intensifying conflict or where elephants enter populated areas. Deploying drones for human-elephant conflict mitigation can also reduce the need for permanent barriers, such as electric fencing, which are broken regularly and have been shown to restrict the movement of wildlife (Kioko et al., 2008; Foley et al., 2008; Durant et al., 2015). The Game Scouts also used the drones to move wildebeest Connochaetes taurinus and zebra Equus quagga out of Tarangire fields in the daytime, suggesting that similar applications to reduce conflict with other wildlife species may be worth exploring (e.g. Ditmer et al., 2015). However, care should be taken to understand the physiological and stress responses of each species before responsibly deploying drones to reduce human-wildlife conflict.

To reduce conflict between people and elephants there is a need for a holistic and adaptive approach that is supported by wildlife managers, engages communities and maintains sufficient space for elephants to thrive. Deploying unmanned aerial vehicles for human-elephant conflict mitigation has limitations, including equipment, training and running costs that may be challenging for wildlife management budgets. In addition, teams were not able to find and respond to all incidents and, in our study area, they depend on existing reporting networks between rangers and farmers. Nonetheless, our results suggest that drone-based methods offer a promising new tool to integrate within a broader suite of proactive, community-based, low-cost mitigation approaches to reduce negative interactions between people and elephants (Hoare, 2015; Karidozo \& Osborn, 2015; Chang'a et al., 2016).

\section{Acknowledgements}

For their continuing interest, support and assistance for this project we thank the Tanzania Wildlife Research Institute, Ministry of Natural Resources and Tourism Wildlife Division-Problem Animal Control Unit, Tanzania National Parks, Tanzania Civil Aviation Authority, Burunge Wildlife Management Area, Ikorongo-Grumeti Village Game Scouts and District Game Officers, the Park Wardens and rangers of Tarangire and Serengeti National Parks, L. Price, L. Stadler, International Elephant Fund, N. Makokecha (DGO-Babati), Said Hewas (Game Warden, Babati District), D. Njapit (Mara Elephant Project), S. Ekeno (Mara Elephant Project), T. Fehsenfeld (Mara Elephant Project), Honeyguide Foundation, N. de Souza, R. Rex (DJI), R. Braun (DJI), D. Polley (Aerial Visions Africa), and several Indiegogo project supporters. This study is dedicated to Lucas Malugu (Tanzania Wildlife Research Institute) and John Muya (Ministry of Natural Resources and Tourism Wildlife Division-Problem Animal Control Unit), who were both great champions of this project, and of wildlife managers, farmers and elephants.

\section{Author contributions}

$\mathrm{NH}, \mathrm{AM}, \mathrm{JK}, \mathrm{NDS}$ and MG were engaged in all aspects of the project, particularly the field trials, training and analysis. $\mathrm{JK}, \mathrm{AC}, \mathrm{SP}, \mathrm{ED}$ and DO were involved in the training, community and government engagement, project authorization, analysis, and manuscript development. 


\section{References}

BARNES, R.F.W. (1999) Is there a future for elephants in West Africa? Mammal Review, 29, 175-200.

Chang'a, A., De Souza, N., Muya, J., Keyyu, J., Mwakatobe, A., MAlugu, L. et al. (2016) Scaling-up the use of chili fences for reducing human-elephant conflict across landscapes in Tanzania. Tropical Conservation Science, 9, 921-930.

Ditmer, M.A., Vincent, J.B., Werden, L.K., Tanner, J.C., Laske, T. G., IAIzzo, P.A. et al. (2015) Bears show a physiological but limited behavioral response to unmanned aerial vehicles. Current Biology, $17,2278-2283$

Durant, S.M., Becker, M.S., Creel, S., Bashir, S., Dickman, A.J., Beudels-Jamar, R.C. et al. (2015) Developing fencing policies for dryland ecosystems. Journal of Applied Ecology, 52, 544-551.

Foley, C., Pettorelli, N. \& Foley, L. (2008) Severe drought and calf survival in elephants. Biology Letters, 4, 541-544.

Graham, M.D. \& Ochieng, T. (2008) Uptake and performance of farm-based measures for reducing crop raiding by elephants Loxodonta africana among smallholder farms in Laikipia District, Kenya. Oryx, 42, 76-82.

HoAre, R.E. (1995) Options for the control of elephants in conflict with people. Pachyderm, 19, 54-63.

HoARe, R.E. (2012) Lessons from 15 years of human-elephant conflict mitigation: management considerations involving biological, physical and governance issues in Africa. Pachyderm, 51, 60-74.

Hoare, R.E. (2015) Lessons from 20 years of human-elephant conflict mitigation in Africa. Human Dimensions of Wildlife, 20, 289-295.

Karidozo, M. \& Osborn, F.V. (2015) Community based conflict mitigation trials: results of field tests of chilli as an elephant deterrent. Journal of Biodiversity \& Endangered Species, 3, 144.

Kioko, J., Muruthi, P., Omondi, P. \& Chiyo, P.I. (2008) The performance of electric fences as elephant barriers in Amboseli, Kenya. South African Journal of Wildlife Research, 38, 52-58.

Langbauer, Jr, W.R. Payne, K.B., Charif, R.A., Rapaport, L. \& Osborn, F. (1991) African elephants respond to distant playbacks of low-frequency conspecific calls. Journal of Experimental Biology, $157,35-46$.

Mwalyosi, R.B. (1981) Ecological changes in Lake Manyara National Park. African Journal of Ecology, 19, 201-204.

Naughton, L., Rose, R. \& Treves, A. (1999) The Social Dimensions of Human-Elephant Conflict in Africa: A Literature Review and Case Studies from Uganda and Cameroon. A Report to the African Elephant Specialist Group, Human-Elephant Conflict Task Force, IUCN, Gland, Switzerland.

O'Connell-Rodwell, C.E., Wood, J.D., Rodwell, T.C., Puria, S., Partan, S.R., Keefe, R. et al. (2006) Wild elephant (Loxodonta africana) breeding herds respond to artificially transmitted seismic stimuli. Behavioral Ecology and Sociobiology, 59, 842-850.

Osborn, F.V. (2002) Capsicum oleoresin as an elephant repellent: field trials in the communal lands of Zimbabwe. The Journal of Wildlife Management, 66, 674-677.
PARKer, G.E. \& Osborn, F.V. (2006) Investigating the potential for chilli Capsicum spp. to reduce human-wildlife conflict in Zimbabwe. Oryx, 40, 343-346.

Parker, G.E., Osborn, F.V., Hoare, R.E. \& Niskanen, L.S. (2007) Human-Elephant Conflict Mitigation: A Training Course for Community-based Approaches in Africa. Participant's Manual. Elephant Pepper Development Trust, Livingstone, Zambia and IUCN/SSC AfESG, Nairobi, Kenya.

Pittiglio, C., Skidmore, A.K., van Gils, H.A., McCall, M.K. \& Prins, H.H. (2014) Smallholder farms as stepping stone corridors for crop-raiding elephant in northern Tanzania: integration of Bayesian expert system and network simulator. Ambio, 43, 149-161.

Poole, J.H. (1999) Signals and assessment in African elephants: evidence from playback experiments. Animal Behaviour, 58, 185-193.

RESOLVE, TAWIRI, TANAPA, MNRT Wildlife Division, Mara Elephant Project (2016) Unmanned Aerial Vehicles as a Tool for Managing African Elephants. Wildlife Manager Training \& Field Trials, Ikorongo-Grumeti Reserve, Tanzania, 27-3o January 2016. Http://maraelephantproject.org/wp-content/uploads/ 2016/04/UAV-Serengeti-Workshop-report_Jan-2016.pdf \& http:// www.resolv.org/site-BiodiversityWildlifeSolutions/files/2014/12/ BWS-RESOLVE-TRAINING-REPORTS-Nov2014-Jan2016.pdf [accessed 21 May 2016].

Sitati, N.W., Walpole, M.J. \& Leader-Williams, N. (2005) Factors affecting susceptibility of farms to crop raiding by African elephants: using a predictive model to mitigate conflict. Journal of Applied Ecology, 42, 1175-1182.

Sitati, N.W., Walpole, M.J., Smith, R.J. \& Leader-Williams, N. (2003) Predicting spatial aspects of human-elephant conflict. Journal of Applied Ecology, 40, 667-677.

Soltis, J., King, L.E., Douglas-Hamilton, I., Vollrath, F. \& SAVAGE, A. (2014) African elephant alarm calls distinguish between threats from humans and bees. PLoS ONE, 9(2), e89403.

\section{Biographical sketches}

Nathan HaHn's research focuses on applying technologies to field conservation challenges. ANGELA MwAKATOBE conducts research on effective ways to mitigate human-wildlife conflicts. JonAtHAN KONUCHE coordinates the unmanned aerial vehicle human-elephant conflict project and trains wildlife managers in the field. NADIA DE So Uza works on human-wildlife conflict issues in East Africa. Juliu s KEYYU supports wildlife research throughout Tanzania. MARC Goss is the lead trainer in the use of drones for mitigating human-elephant conflict, and works to reduce poaching and human-elephant conflict in the Mara Ecosystem using a range of tools. Alex CHANG'A works with government and communities to find solutions to human-elephant conflict throughout Tanzania. Suzanne Palminteri is a conservation biologist and tests methods for resolving human-elephant conflict. ER IC Dinerstein applies technological advances to conservation practice. DAvid Olson is a conservation biologist with an interest in practical solutions to conservation challenges. 